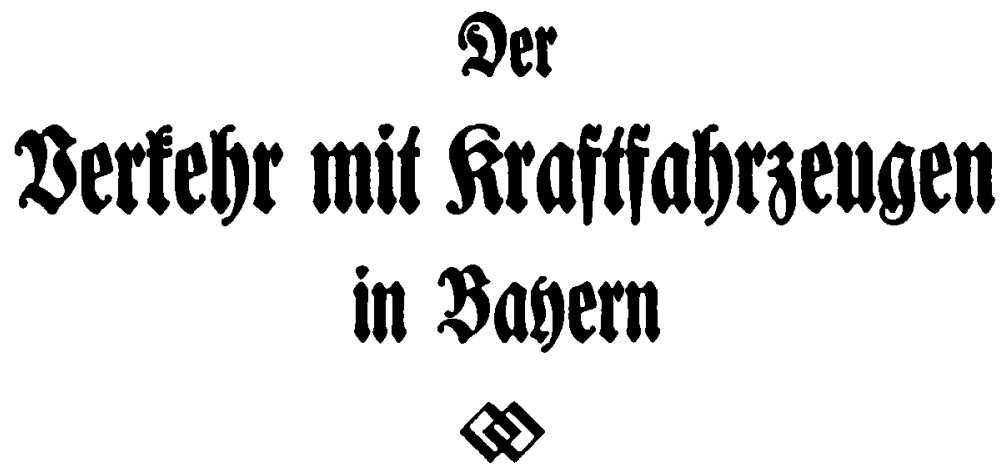

Beieh uno Beroronung äber Srafffahrzeugbertehr mit Crläuterungen und Boflzugsborínriften.

\title{
II. ఇeil.
}

1. 2uflage.

Dearbeitet von

Dr. jur. Walther v. Sellingratf und Dr. jur. Zluguft Midjel

Genbarmeriehauptmann I. FT.

bei ber Reglerung von Ediwaben unb Neuburg, Я. b. I.
Reglerungzaffeffor

bef ber Hegierung von Şłwaben unb Reuburg, R. D. $\mathfrak{I}$.

1928

2Ränden, Berlin und Eefpoig 3. Gqweliber Berlag (artbur Gellier). 
